\title{
Adult Rat Bone Marrow-Derived Stem Cells Promote Late Fetal Type II Cell Differentiation in a Co-Culture Model
}

\author{
A.B. Knoll ${ }^{1,2}$, T. Brockmeyer ${ }^{1,2}$, R. Chevalier ${ }^{2,3}$, K. Zscheppang ${ }^{1,2}$, H.C. Nielsen ${ }^{2,4}$ \\ and C.E. Dammann ${ }^{*}, 1,2,4$ \\ ${ }^{1}$ Hannover Medical School, Hannover, Germany \\ ${ }^{2}$ Division of Newborn Medicine, Floating Hospital for Children at Tufts Medical Center, Boston, MA, USA \\ ${ }^{3}$ West Virginia University School of Medicine, Morgantown, WV, USA \\ ${ }^{4}$ Sackler School of Graduate Biomedical Sciences, Tufts University Boston, MA, USA
}

\begin{abstract}
Bronchopulmonary dysplasia develops in preterm infants due to a combination of lung immaturity and lung injury. Cultured pluripotent bone marrow stem cells (BMSC) are known to reduce injury and induce repair in adult and in immature lungs, possibly through paracrine secretion of soluble factors. The paracrine relationship between BMSC and primary fetal lung epithelial type II cells is unknown. We determined the effects of BMSC on type II cell and fibroblast behavior using an in vitro co-culture model. Rat BMSC were isolated and co-cultured with primary fetal E21 rat type II cells or lung fibroblasts in a Transwell ${ }^{\circledR}$ system without direct cell contact. Effects of BMSC conditioned media (CM) on type II cell and fibroblast proliferation and on type II cell surfactant phospholipid (DSPC) synthesis and mRNA expression of surfactant proteins B and C ( $s f t p b$ and $s f t p c)$ were studied. We also determined the effect of fibroblast and type II cell CM on BMSC proliferation and surface marker expression. Co-culture with BMSC significantly decreased type II cell and fibroblast proliferation to $72.5 \%$ and $83.7 \%$ of controls, respectively. Type II cell DSPC synthesis was significantly increased by $21 \%$ and $s f t p b$ and $s f t p c$ mRNA expressions were significantly induced (2.1 fold and 2.4 fold, respectively). BMSC proliferation was significantly reduced during the co-culture. Flow cytometry confirmed that BMSC retained the expression of undifferentiated stem cell markers despite their exposure to fetal lung cell CM. We conclude that BMSC induce fetal type II cell differentiation through paracrine release of soluble factors. These studies provide clues for how BMSC may act in promoting alveolar repair following injury.
\end{abstract}

Keywords: Lung development, surfactant, proliferation, co-culture, lung fibroblasts.

\section{INTRODUCTION}

Bronchopulmonary dysplasia (BPD) develops in preterm infants as a combination of an injury-induced arrest of lung maturation and altered remodeling [1-4]. Preterm birth represents an increasing challenge in obstetric and neonatal medicine $[5,6]$ and despite major advances in prenatal and postnatal care, the incidence of BPD in preterm infants remains constant [7]. Safe and effective strategies for prevention or treatment of BPD remain elusive [8].

In the past decade several studies have concentrated on the use of bone marrow derived mesenchymal stem cells (BMSC) as a promising new therapeutic approach for lung injury. The potential of BMSC to protect lung tissue from injury by reducing inflammation and development of fibrosis has been frequently demonstrated [9-11]. In neonatal lungs the application of BMSC attenuates the effects of hyperoxiainduced lung injury $[12,13]$. The protective effects of BMSC have been attributed to different mechanisms: BMSC have

*Address correspondence to this author at the Division of Newborn Medicine, Floating Hospital for Children at Tufts Medical Center, 800 Washington St, Boston, MA 02111, USA; Tel: (617) 636-8738; Fax: (617) 636-4233; E-mail: cdammann@tuftsmedicalcenter.org been reported to engraft into the injured lung and to transdifferentiate into lung epithelium $[9,10,14-17]$ or to fuse with lung cells to form chimeric cells $[18,19]$. More recent studies have challenged the idea that BMSC transdifferentiate to take on the phenotype of lung epithelial cells $[20,21]$ and suggested that BMSC effects are mediated via paracrine mechanisms $[12,13]$. We hypothesized that soluble factors secreted by BMSC exert positive effects on growth and differentiation of fetal lung alveolar type II cells and fibroblasts. To evaluate this hypothesis we used a rat coculture model without direct BMSC-lung cell contact and studied parameters of growth and differentiation of the fetal cells.

\section{MATERIALS AND METHODS}

\section{Study Protocol}

(Fig. 1) presents a chart flow showing the design of the experiments and the specific outcomes measured. Fetal rat lung type II cells or fibroblasts were co-cultured with adult rat BMSCs using Transwell ${ }^{\mathbb{R}}$ inserts. In this way cells were able to communicate without direct cell contact. This coculture system, as shown in Fig. (1), was set up in several ways. Each cell type was grown on plastic in one group of experiments and on the inserts in a second group of 

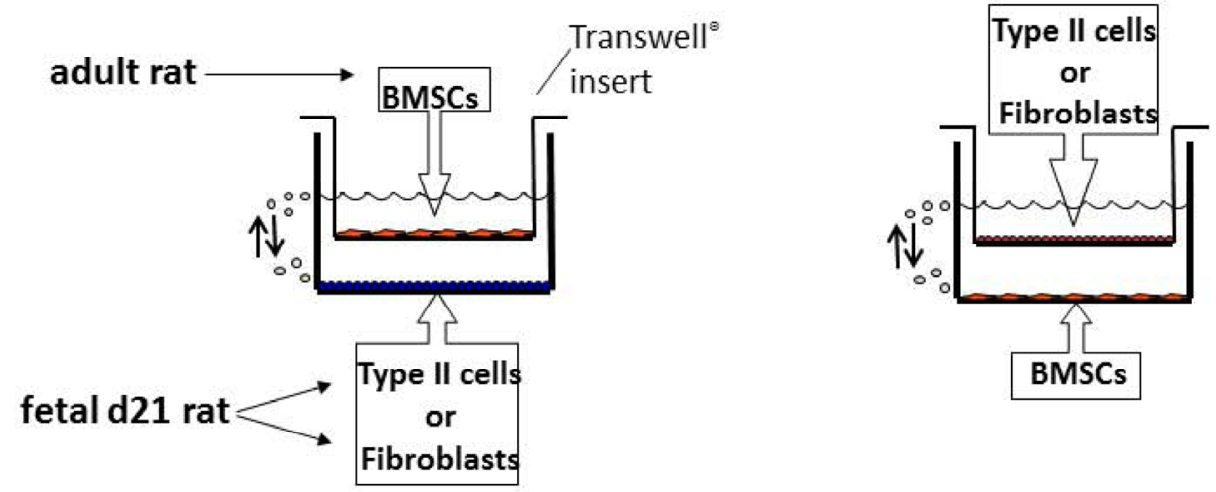

Fig. (1). Schematic of study flow design. Co-cultures were prepared with either fetal rat lung fibroblasts or type II cells cultured on the bottom of 6-well plates with BMSC cultured on the Transwell ${ }^{\circledR}$ insert, or BMSC cultured on the bottom of the plates with either fetal rat lung fibroblasts or type II cells cultured on the Transwell ${ }^{\circledR}$ insert. All cell studies were performed on the cells cultured on the plate bottoms after 48 hours of co-culture. Cell proliferation was measured by thymidine incorporation. Differentiated type II cell-like function was studied by choline incorporation into DSPC. Cell surface markers that help define BMSC were studied by flow cytometry in the BMSC only.

experiments. After 48h we studied: 1) proliferation (by thymidine incorporation) in the type II cells, the fibroblasts and the BMSCs cultured on plastic; 2) surfactant synthesis (choline incorporation into disaturated phosphatidylcholine (DSPC)) in each cell cultured on plastic; and 3) cell surface markers using flow cytometry of the BMSCs cultured on plastic. The specific procedures for these studies are described in the following paragraphs.

\section{Preparations of Primary Fetal Rat Fibroblast and Type II Cell Cultures}

The animal research protocol was approved by the institutional IACUC. Time-dated pregnant Sprague-Dawley rats were sacrificed on $\mathrm{E} 21$ of gestation by $\mathrm{CO}_{2}$ inhalation as previously published [22]. Briefly, the fetal lungs were removed, washed in Hank's buffered saline solution (HBSS), minced with a razor blade, dissociated in HBSS containing $0.25 \%$ trypsin and $20 \mu \mathrm{g} / \mathrm{ml}$ DNAse and incubated at $37^{\circ} \mathrm{C}$ for 12 minutes. The reaction was stopped by DMEM containing $10 \%$ charcoal stripped fetal bovine serum (FBS ${ }^{-}$). The cells were filtered through sterile Nitex filters and centrifuged for 10 minutes at $650 \mathrm{x} \mathrm{g}$ at $4{ }^{\circ} \mathrm{C}$. The pellet was resuspended in DMEM containing $10 \% \mathrm{FBS}^{-}$, the cells were plated in culture dishes, and incubated for 45 minutes at $37^{\circ} \mathrm{C}\left(21 \% \mathrm{O}_{2} / 5 \% \mathrm{CO}_{2}\right)$ to allow the differential adherence of lung fibroblasts. Dishes with adherent fibroblasts were washed with DMEM, then DMEM containing 10\% $\mathrm{FBS}^{-}$ was added and the cells were incubated at $37^{\circ} \mathrm{C}$ overnight. The supernatant containing non-adherent type II cells was removed and centrifuged for 5 minutes, the pellet was resuspended in DMEM containing $10 \%$ FBS $^{-}$and the cells were plated into culture dishes and incubated for 60 minutes at $37^{\circ} \mathrm{C}$ for a second differential adherence. The supernatants were again collected and centrifuged. The pellet was resuspended in DMEM containing 20\% $\mathrm{FBS}^{-}$and the cells were plated at a concentration of $0.7 \times 10^{6} / \mathrm{ml}$ into $24-$ or 6well tissue culture plates or cell culture inserts overnight. Non-adherent cells were washed away with DMEM.

\section{Mesenchymal Stem Cell Harvest and Cell Culture}

Bone marrow derived mesenchymal stem cells (BMSC) were kindly provided by Dr. Bernard Thébaud (University of Alberta, Alberta, Edmonton Canada). The BMSC were harvested from adult Sprague-Dawley rats by excising the femur and tibia and flushing the marrow with DMEM as previously published [12]. The isolated marrow was dissociated with a 21-gauge needle and plated into a tissue culture flask. After overnight adherence, the media was aspirated, adherent cells were rinsed with PBS, and the media was replenished. Adherent cells were allowed to grow to $\sim 75 \%$ confluence, then trypsinized and reseeded at a density of $10^{5}$ cells $/ \mathrm{cm}^{2}$. This procedure was performed for 2 passages. Cells were then shipped to Tufts Medical Center, where they were immediately placed in culture and expanded for further use. Experiments were done with BMSC that had undergone a total of $4-6$ passages.

\section{Co-Culture Model}

BMSC were plated into 24- or 6-well tissue culture plates or onto cell culture inserts with DMEM $+10 \%$ FBS $^{-}$. Type II cells plated in the wells were exposed to BMSC- or fibroblast-conditioned media $(\mathrm{CM})$ by placing inserts plated with BMSC or fibroblasts into the wells with type II cells, allowing the cells to grow in the same medium (DMEM with $10 \% \mathrm{FBS}^{-}$) without direct contact between the type II cells and either the BMSC or the fibroblasts. Fibroblasts plated in the wells were exposed to BMSC conditioned media in the same manner. BMSC plated in the wells were exposed similarly to type II cell or fibroblast conditioned media. All cells were harvested after 48 hours of co-culture.

\section{$\left[{ }^{3} \mathrm{H}\right]$ Thymidine Incorporation}

Type II cells and fibroblasts exposed to BMSC CM and BMSC exposed to type II cell or fibroblast $\mathrm{CM}$ were serum starved for 2 hours and exposed to $\left[{ }^{3} \mathrm{H}\right]$ thymidine $(0.5$ $\mu \mathrm{Ci} / \mathrm{ml}$ ) for an additional 24 hours in serum-free DMEM. Cells were washed three times with ice-cold PBS and detached with trypsin. Total DNA was measured in duplicate aliquots and used as an internal standard. The cells were transferred into scintillation fluid and incorporated $\left[{ }^{3} \mathrm{H}\right]$ thymidine was counted in a beta scintillation counter as previously published [23]. The results from exposed cells were expressed as percent of sample-specific non-exposed control cells. 


\section{$\left[{ }^{3} \mathrm{H}\right]$ Choline Incorporation}

Type II cells were co-cultured with BMSC, and BMSC were co-cultured with type II cells for 24 hours and exposed to $\left[{ }^{3} \mathrm{H}\right]$ choline $(0.5 \mu \mathrm{Ci} / \mathrm{ml})$ for an additional 24 hours. Cells were washed three times with ice cold PBS, lysed in trypsin, and sonicated. Total protein amount per sample was measured in duplicate aliquots and used as an internal standard. Chloroform/methanol extraction of lipids was performed as previously described [23]. Disaturated phosphatidylcholine (DSPC) was isolated from the extracted lipids by osmium tetroxide and separated by thin-layer chromatography on silica gel $\mathrm{H}$ chromatography sheets. The resulting spots were scraped into scintillation fluid, counted in a beta scintillation counter, expressed as disintegrations per min per $\mu \mathrm{g}$ protein, and the results expressed as percent of sample specific controls.

\section{Quantitative Real Time PCR}

RNA was harvested on day 3 of culture using a Qiagen RNeasy MicroKit. The first strand complementary DNA was synthesized using the Super Script ${ }^{\mathrm{TM}}$ III Reverse Transcriptase Kit with oligonucleotide dTs $(0.5 \mu \mathrm{g} / \mu \mathrm{l})$. The cDNA levels from the surfactant proteins B and C (sftph, sftpc), and actin gene transcripts were measured by real-time PCR. One microgram of the cDNA product was used for amplification in a $20 \mu 1$ reaction volume containing $10 \mu 1$ SYBR Green PCR Master Mix, $7 \mu 1$ DEPC- $\mathrm{H}_{2} \mathrm{O}$ and $1 \mu 1$ forward and reverse primers [24]. The amplification protocol consisted of an initial denaturation and enzyme activation at $95^{\circ} \mathrm{C}$ for 10 minutes, followed by a DNA amplification with 40 cycles each consisting of 30 seconds at $95^{\circ} \mathrm{C}$, an attachment of primers for 1 minute at $55^{\circ} \mathrm{C}$, and the extension at $72^{\circ} \mathrm{C}$ for 30 seconds, and finally 1 cycle at $72^{\circ} \mathrm{C}$ for $10 \mathrm{~min}$ for final elongation. The relative expression level of the sftp genes was calculated by calculating the delta (D)Ct value representing the difference in the $\mathrm{Ct}$ values of the target and the reference gene. From this, the DDCt value was calculated as the difference between the DCt of cocultured cells and their non-exposed controls. The DDCt value, which is a negative number when the treatment condition is stimulated compared to the control condition, is a standard representation of comparative real time PCR results. The value $[-(\mathrm{DDCT})]$ is the power to which 2 is raised to calculate fold changes in mRNA levels between treatment and control conditions. The DDCt therefore is geometrically proportional to the change in levels of $s f t p$ mRNA [25].

\section{Flow Cytometry}

On day 3 of culture cells were harvested, centrifuged, resuspended in 5\% normal horse serum, and incubated with the primary antibody for 0.5 hours at $4{ }^{\circ} \mathrm{C}$. The cells were washed with PBS and probed with the appropriate secondary antibody. After an incubation time of 30 minutes at $4{ }^{\circ} \mathrm{C}$, cells were washed extensively with PBS, transferred into icecold PBS containing $0.5 \%$ BSA, and kept in BD Falcon tubes on ice until read in the Beckman-Counter MoFlo high speed sorter.

\section{Data Analysis}

The effects of BMSC CM exposure on proliferation and surfactant synthesis were expressed as percentages of their specific non-treated controls. All treatment values are presented as mean \pm SEM of experiment-specific controls unless otherwise stated. The results were evaluated for statistical significance using a two-tailed t-test or a MannWhitney $U$ test and corrected for multiple comparisons when appropriate.

\section{Specific Reagents}

Timed pregnant Sprague-Dawley rats were obtained from Taconic Farms (Germantown, NY); plastic tissue culture dishes, 6- and 24-well culture plates, and 6- and 24 Transwell $^{\circledR}(0.4 \mu \mathrm{m}$ pore sized $)$ cell culture inserts were obtained from Becton Dickinson Labware (Franklin Lakes, $\mathrm{NJ}) .\left[{ }^{3} \mathrm{H}\right]$ choline (specific activity $70.3 \mathrm{Ci} / \mathrm{mmol}$ ) $\left[{ }^{3} \mathrm{H}\right]$ thymidine (specific activity $20.0 \mathrm{Ci} / \mathrm{mmol}$ ), Dulbecco's modified eagle's medium (DMEM), dipalmitoylphosphatidylcholine (DSPC) standard and osmium tetroxide were from Sigma Aldrich (St. Louis, MO). Charcoal-stripped fetal bovine serum was from Hyclone (Logan, UT); silica gel-coated PE sheets came from Analtech (Newark, CE). Antibodies were obtained as follows: mouse monoclonal $\mathrm{IgG}$ anti CD54 antibody and goat polyclonal IgG anti CD105 antibody were from Santa Cruz Biotechnology (Santa Cruz, CA); mouse monoclonal IgG anti CD90 antibody and mouse monoclonal IgG anti CD45 antibody were from Cedarlane (Burlington, NC); mouse monoclonal IgG anti CD73 antibody was from BD Bioscience Pharmingen (Franklin Lakes, NJ); monoclonal anti- $\beta$ Actin was from Sigma (St. Louis, MO); Alexa Fluor secondary antibody 488 was from Invitrogen (Eugene, OR). PCR primers for actin, sftpb and sftpc were obtained from the Tufts Medical Center Core Facility (Boston, MA). RNeasy Micro Kit was from Qiagen (Valencia, CA), SuperScript ${ }^{\mathrm{TM}}$ III Reverse Transcriptase Kit was from Invitrogen (Carlsbad, CA), and SYBR Green PCR Master Mix was from Stratagene (La Jolla, CA).

\section{RESULTS}

\section{Exposure to CM Reduces Cell Growth}

Purity of type II cells was confirmed by staining [26] and was more than $92 \%$ as we have previously published [27]. BMSC CM exposure significantly decreased type II cell proliferation to $72.5 \pm 7.1 \%(\mathrm{n}=8, \mathrm{p}=0.009)$ compared to non-exposed control type II cells $(100 \pm 7.6 \%, \mathrm{n}=8)$ (Fig. 2$)$. Fetal lung fibroblast proliferation decreased to $83.7 \pm 8.7 \%$ $(\mathrm{n}=8, \mathrm{p}=0.16)$ when exposed to BMSC CM compared to non-exposed fibroblasts (100 $\pm 6.2 \%, \mathrm{n}=8)$ (Fig. 2). Proliferation of BMSC was significantly reduced to $72.2 \pm$ $5.8 \%$ (mean $\pm \mathrm{SE}, \mathrm{n}=8, \mathrm{p}<0.001)$ when co-cultured with type II cells, and to $76.2 \pm 3.2 \%$ (mean $\pm \mathrm{SE}, \mathrm{n}=8, \mathrm{p}<0.001)$ when exposed to fibroblasts, compared to BMSC grown in monoculture (100 $\pm 3.9 \%)$ (Fig. 2).

\section{Exposure to BMSC CM Induces Surfactant Synthesis in Fetal Type II Cells}

As a marker of surfactant phospholipid synthesis we measured the amount of incorporated $\left[{ }^{3} \mathrm{H}\right]$ choline into DSPC in type II cells with and without exposure to BMSC CM. Surfactant phospholipid synthesis was significantly increased to $84.0 \pm 8.3$ disintegrations $/ \mathrm{min} / \mu \mathrm{g}$ protein $(121.1$ $\pm 9.6 \%$, mean \pm SE, $n=7, p=0.046$ ) in fetal primary type II cells when co-cultured with BMSC compared to type II cells 


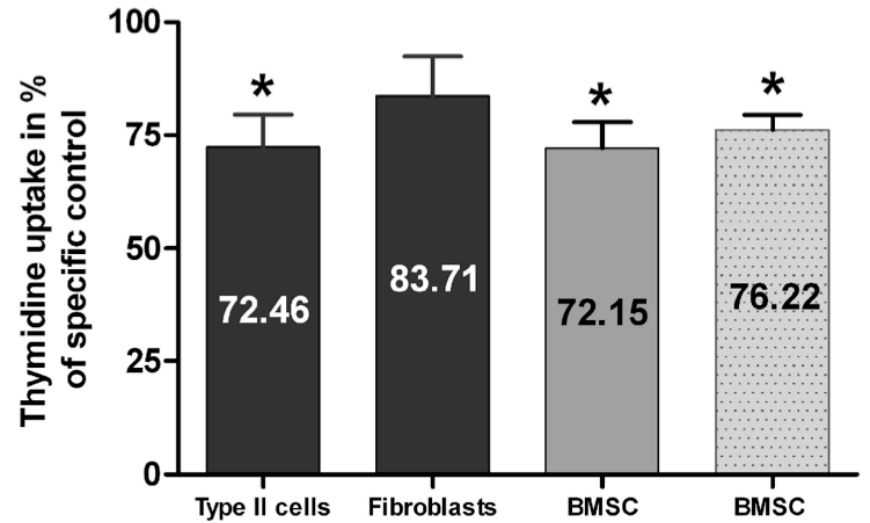

Fig. (2). Paracrine effects on cell growth: Paracrine effects of BMSC (bar 1+2) on the proliferation of fetal rat $\mathrm{d} 21$ type II cells and fibroblasts and of type II cells (3. grey bar) and fibroblasts (4. light grey bar) on proliferation of BMSC. Proliferation was measured by thymidine incorporation. Results are expressed as percent changes of their specific untreated controls and presented as Mean \pm SEM $\left(\mathrm{n}=8,{ }^{*} \mathrm{p}<0.05\right)$.

cultured without BMSC exposure $(67.92 \pm 6.4$ disintegrations $/ \mathrm{min} / \mu \mathrm{g}$ protein, $100 \pm 4.4 \%, \mathrm{n}=7$ ) (Fig. 3). This increase after BMSC CM exposure is similar to, albeit less than, the stimulatory effect of fibroblast CM or NRG1- $\beta$ on type II cell DSPC as reported in the literature [23,24,28], which we have studied previously. Exposure of BMSC to either fetal lung fibroblast or type II cell CM did not induce the BMSC to incorporate choline into DSPC (data not shown), confirming that they have not been induced to transform into lung type II cells.

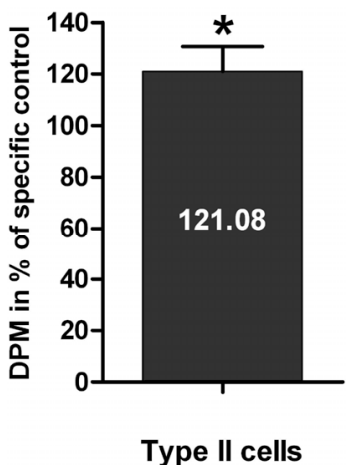

Fig. (3). Paracrine effects of BMSC on type II cell surfactant synthesis: The paracrine effects of BMSC (black bars) on fetal rat d21 type II cell surfactant DSPC synthesis was measured by choline incorporation into DSPC. Results are expressed as percent changes of their specific untreated controls and presented as Mean \pm SEM $\left(\mathrm{n}=7,{ }^{*} \mathrm{p}<0.05\right)$.

\section{BMSC CM Stimulates Fetal sftpb and sftpc mRNA Expression More than Fibroblast CM}

We then studied the effect of BMSC CM on sftpb and $s f t p c$ mRNA in type II cells and compared it to the known stimulatory effect of fetal lung fibroblast CM on type II cell surfactant protein mRNA expression. Co-culture with BMSC significantly increased $s f t p b$ mRNA expression in type II cells: DCt of $s f t p b / a c t i n$ was $7.6 \pm 0.5$ cycles for type II cells exposed to BMSC CM compared to $9.6 \pm 0.3$ cycles for non exposed control type II cells. The DDCt between treatment and control was $-2.1 \pm 0.5(\mathrm{n}=6, \mathrm{p}=0.002)$. The increase in $s f t p b$ mRNA expression was similar to the stimulatory effect of fibroblast CM: the DCt for sftpb/actin was $7.7 \pm 0.5$ cycles, the DDCt between treatment and control was $-1.9 \pm$ $0.4(n=5, p=0.003)$ (Fig. 4A). The stimulatory effects of both conditioned media were in alignment with our previous published effect of NRG on Sftpb mRNA, though somewhat more potent $[28,29]$.

However, BMSC CM stimulation of sftpc mRNA expression (DDCt -2.4 $\pm 0.8 ; \mathrm{n}=5, \mathrm{p}=0.065)$ was significantly $(p=0.035)$ more pronounced than that of fibroblast CM (DDCt $-0.5 \pm 0.4 \mathrm{n}=6, \mathrm{p}=0.33$ ). The $\mathrm{DCt}$ value of sftpc/actin was $10.0 \pm 0.3$ cycles for type II cells alone, $9.3 \pm 0.5$ for type II cells exposed to fibroblast $\mathrm{CM}$ and $7.9 \pm 1.0$ for type II cells exposed to BMSC CM. (Fig. 4B).

(A)

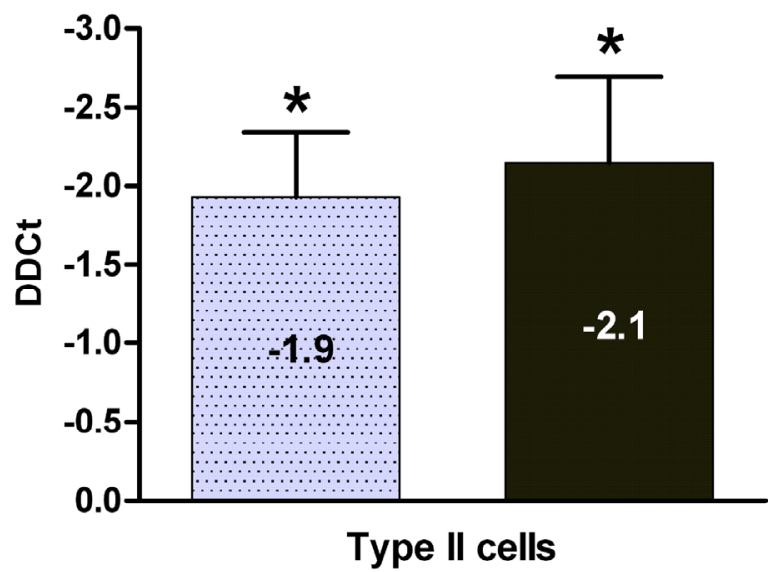

(B)

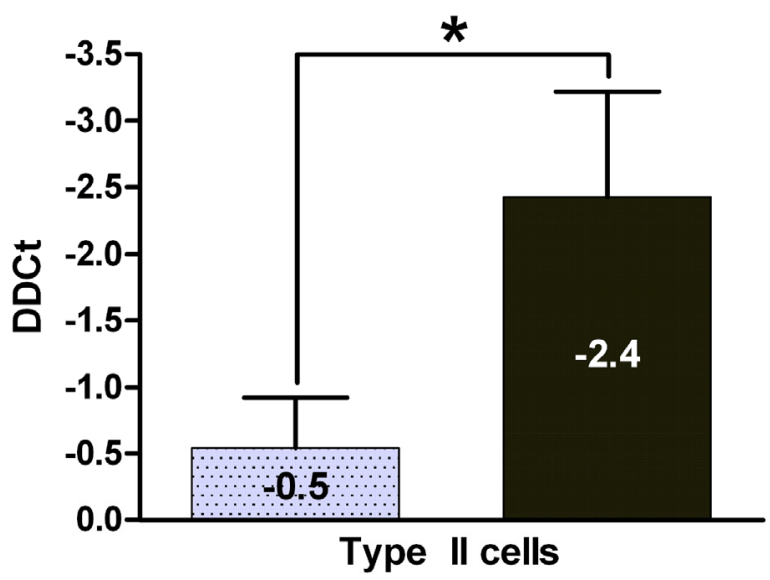

Fig. (4). Paracrine effects of BMSC and fetal lung fibroblasts on $S f t p b$ and $S f t p c$ mRNA expression in fetal type II cells: Fetal rat E21 type II cells were grown in co-culture with fetal lung fibroblasts (light grey bar) or BMSC (black bar) and the paracrine effects on $s f t p b$ mRNA (A) and $s f t p c$ mRNA (B) expression evaluated. Results are displayed as the DDCt and presented as Mean \pm SEM $\left(n=4,{ }^{*} p<0.035\right)$. A negative DDCT value represents an increase in expression.

Expression of Surface Markers by BMSC is Not Changed by Exposure to Fetal Lung Fibroblasts or Type II Cells

BMSC used for all experiments are able to differentiate into adipogenic, osteogenic and chondrogenic tissue and 
$\operatorname{CD} 90$

BMSC

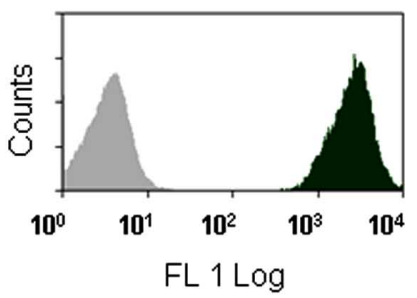

BMSC FCM

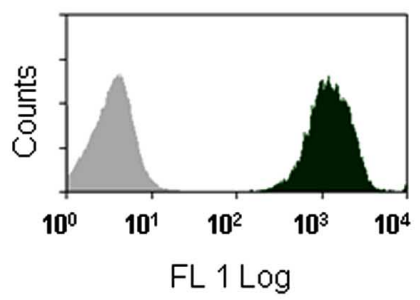

BMSC TCM

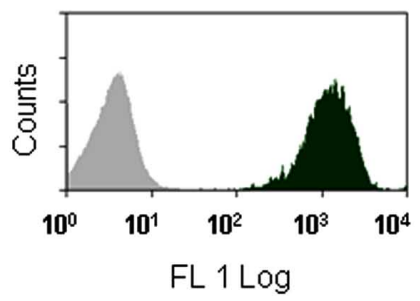

CD 105
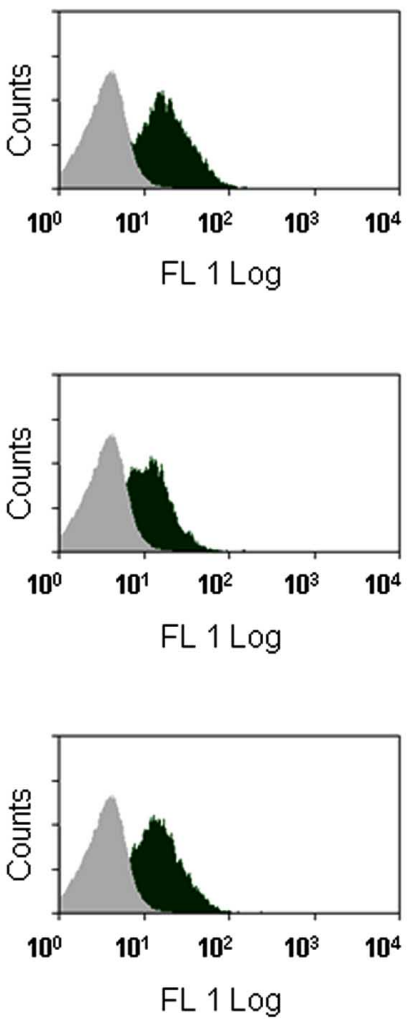

CD 54
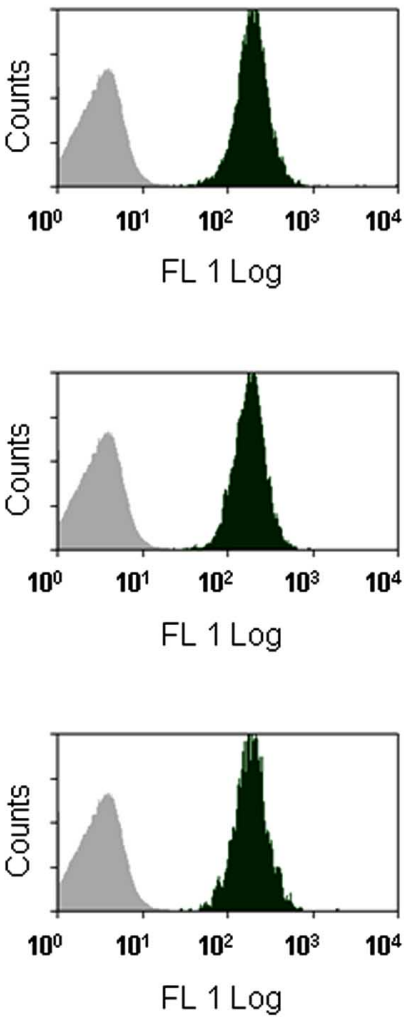

Fig. (5). Paracrine effects of fetal lung fibroblasts and type II cells on BMSC surface marker expression: The effect on BMSC marker expression after co-culture with fetal lung fibroblasts (FCM) and type II cells (TCM) for $48 \mathrm{~h}$ was analyzed by fluorescence activated cell sorting (FACS) and compared to non-exposed BMSC. Representative fluorescence intensity histograms with specific antibodies for membrane antigens (green area) and a negative control (grey area) are shown. Experiments were performed in quadruplicate.

express CD90, CD73, CD105, CD54, CD44, but do not CD31 and CD45 [12]. These characteristics comply with the position statement for minimal criteria to define MSC [30]. We followed the expression patterns of CD90, CD73, CD105, CD54, and CD45 as markers of multipotent mesenchymal stem cell characteristics, before and after the exposure to lung cell CM. BMSC stained positive for CD90, CD105, CD54, and CD73 (data not shown), with no change after fibroblast $\mathrm{CM}(\mathrm{n}=4)$ or type II cell $\mathrm{CM}$ exposure $(\mathrm{n}=4)$, (Fig. 5). The BMSC stained negative for CD45 in all three conditions (data not shown).

\section{DISCUSSION}

BMSC are multipotent mesenchymal stem cells with the capacity to differentiate into osteocytes, chondrocytes, and adipocytes $[31,32]$. Administration of BMSC in lung injury models can attenuate lung injury [9-13], but it is increasingly controversial whether this effect is caused by engraftment into the lung, or proliferation and trans-differentiation to replace damaged tissue, as has been speculated earlier $[20,21]$. There is, on the other hand, increasing evidence, specifically in neural tissue, that cell-free CM from stem cells effectively repairs injury by paracrine mechanisms via trophic factors secreted from the stem cells [33]. Evidence suggests that trophic factors work in conjunction with other factors in the conditioned media to promote repair and survival [34,35]. In the present study we address the hypothesis that BMSC affect the developing fetal type II cells and fibroblasts via paracrine mechanisms. Fetal type II cells are more phenotypically stable than adult type II cells in culture, allowing studies of the effects of BMSC CM to be more readily performed.

Co-culturing mature fetal type II cells and BMSC significantly decreased the proliferative activity of the respective other cell type. At the same time surfactant synthesis and $s f t p b$ and $s f t p c$ expression were significantly increased in the fetal type II cells. Our data indicate that fetal type II cell maturation was enhanced in response to paracrine factors secreted by BMSC. Similar effects have previously been published for fetal lung fibroblast $\mathrm{CM}$ on both rat and mouse lung epithelial type II cell differentiation $[23,36]$. In the developing lung, fibroblasts promote surfactant synthesis in type II cells through paracrine activity [23,36,37]. In this study, BMSC stimulated surfactant synthesis and sftpb mRNA expression to a degree similar to fibroblast CM [23]. The increase of $s f t p c$ mRNA expression induced by BMSC $\mathrm{CM}$ was even more pronounced than by the fibroblast CM, suggesting that BMSC may release additional or more potent mediators to increase $s f t p c$ expression in type II cells.

Type II cells cultured from adult rats show a change of phenotype in culture, losing the expression of surfactant 
proteins and surfactant phospholipids after 48 hours and expressing markers of type I cells. This in vitro pleiotropism is significantly delayed or absent in cultured fetal type II cells. We have shown that cultured fetal type II cells maintain their type II cell phenotype for at least 5 days $[27,29,37]$. We recognize that while our type II cell cultures are $>90 \%$ pure type II cells, this leaves a small fraction of other cells, primarily fibroblasts, which could influence the results. Multiple studies by ourselves and others have documented the positive effects on surfactant phospholipid and surfactant protein production by fibroblast conditioned media and by specific growth factors such as neuregulin, leptin and KGF on type II cell cultures of this purity [27,29,37-39]. These studies, using proper controls, indicate that the major influence on cultured type II cells is from exogenous sources rather than the small percentage of nontype II cells in the culture. Thus, our results are likely to reflect fetal type II cell responses to the co-cultured cells.

We have not yet studied the combined effects of fibroblast and BMSC CM. Preterm infants with dysfunctional surfactant, who are at risk of developing RDS and consequently BPD, frequently lack appropriate expression of both $\mathrm{sftpb}$ and $\mathrm{s} f t p c$ [40]. Thus there is potential value of BMSCs in the injured preterm lung through enhancement of type II cell function over that provided by the microenvironmental niche of endogenous mesenchymal-epithelial interactions.

Our finding that BMSC CM provoked decreased proliferation in co-culture differs from studies by other investigators, who found proliferation-promoting capacities of BMSC secreted factors when cultured in isolation [41,42]. These studies, however, examined the effects on adult cells, and not, as we have done here, on fetal cells, which are still in a developmental stage. It is a generally recognized phenomenon of development that as maturation is promoted, proliferation is downregulated as a trade off $[43,44]$. This may relate to mechanisms associated with initiation of differentiation in developing cells, where the major focus is activity transitions from cellular proliferation to maturation [44].

Similar effects on lung maturation as were found to be mediated by BMSC in this study are induced by glucocorticoids, which are potent anti-inflammatory agents that modulate levels of anti-inflammatory cytokines and growth factors [45-47]. Glucocorticoids promote lung maturation [48], DSPC synthesis in preterm infants in vivo [49], and expression of the surfactant protein mRNAs [50]. Keratinocyte growth factor (KGF) has been postulated to be a possible mediator of those glucocorticoid-effects on type II cells [50]. KGF is also expressed by lung mesenchyme (39, 40 ), and is known to be essential for lung development; in particular, KGF induces an increase in surfactant DSPC synthesis and expression of three of the four surfactant protein genes, namely $\mathrm{s} f t p a, \mathrm{~s} f t p b$, and $s f t p c$ in fetal rat type II cells [51,52] and KGF exhibits protective functions on injured lung epithelia $[53,54]$. Recent studies have shown that BMSC can secrete KGF [55]. Therefore KGF may mediate at least some of the effects of BMSC on fetal type II cells.

Another factor capable of promoting surfactant expression via mesenchymal-epithelial interactions in developing type II cells is NRG [23], which signals its effect on the developing type II cells through the ErbB4 receptor and its direct interaction with important transcription factors [24]. ErbB4 is an important promoter of the timely progression of lung development [56]; its deletion leads to a lung phenotype similar to BPD with alveolar simplification and a hyperreactive airway system [57]. NRG has been suggested as an endogenous protector for perinatal brain damage [58], but its role in perinatal lung injury has not been elucidated.

Throughout the exposure to cultured fetal lung type II cells or fibroblasts, BMSC continued to express the same surface markers, characterizing them as multipotent, undifferentiated cells. We found no evidence of BMSC transdifferentiation into lung epithelial cells. However, the decrease of BMSC proliferation can be viewed as an indication that not BMSC growth but their secretion of factors is promoted by the fetal lung cell environment, which in turn promotes type II cell maturation over their proliferation activity.

We focused on clearly observable effects of BMSC CM on fetal lung cell growth and function, highly likely to be regulated through soluble factors. New questions are raised by this work. Additional studies are needed to identify the soluble factors involved in the paracrine effect of transplanted BMSC following lung injury. Further, it is unknown what sources of stem cells are most important in repair after lung injury in vivo. In addition to BMSC it is possible that amniotic fluid stem cells resident in the neonatal lung, or endogenous lung stem or progenitor cell populations are the major mediators in injury repair.

\section{CONCLUSIONS}

In summary, we here show that BMSC CM promote fetal type II cell maturation via paracrine mechanisms. Further studies are needed to focus on differences in the effect of $\mathrm{CM}$ from BMSC not exposed to lung cells, exposed to injured lung cells or simultaneously co-exposed to injury, a condition in which BMSC induce an even more prominent rescue in the neurological system [59]. We here suggest that the repair and amelioration of lung damage seen in animal models $[12,13]$ given BMSC following injury is at least in parts due to the secretion of soluble factors by the BMSC in the alveolar microenvironment. Whether BMSC are major effectors of lung repair after injury in vivo remains to be elucidated.

\section{CONFLICT OF INTEREST}

The studies were funded by the National Heart, Lung, and Blood Institute NIH HL037930 and NIH 085648, the Society for Pediatric Research Student Research Program, and the Susan B. Saltonstall Funds. The authors do not have any conflict of interest to declare.

\section{ACKNOWLEDGEMENTS}

We thank Dr. Jonathan Davis for his valuable support and discussions. We would also like to thank Dr. Washa Liu for her involvement in training Dr. Knoll, Dr. Brockmeyer and Dr. Chevalier. We thank Dr. Bernard Thébaud for supplying us with the BMSC. 


\section{REFERENCES}

[1] Bose CL, Dammann CE, Laughon MM. Bronchopulmonary dysplasia and inflammatory biomarkers in the premature neonate. Arch Dis Child Fetal Neonatal Ed 2008; 93: F455-61.

[2] Hayes D Jr, Feola DJ, Murphy BS, Shook LA, Ballard HO. Pathogenesis of bronchopulmonary dysplasia. Respiration 2010; 79: 425-36.

[3] Kinsella JP, Greenough A, Abman SH. Bronchopulmonary dysplasia. Lancet 2006; 367: 1421-31.

[4] Jobe AH, Bancalari E. Bronchopulmonary dysplasia. Am J Respir Crit Care Med 2001; 163: 1723-9.

[5] Goldenberg RL, Culhane JF, Iams JD, Romero R. Epidemiology and causes of preterm birth. Lancet 2008; 371: 75-84.

[6] Beck S, Wojdyla D, Say L, et al. The worldwide incidence of preterm birth: a systematic review of maternal mortality and morbidity. Bull World Health Organ 2010; 88: 31-8.

[7] Smith VC, Zupancic JA, McCormick MC, et al. Trends in severe bronchopulmonary dysplasia rates between 1994 and 2002. J Pediatr 2005; 146: 469-73.

[8] Baveja R, Christou H. Pharmacological strategies in the prevention and management of bronchopulmonary dysplasia. Semin Perinatol 2006; 30: 209-18.

[9] Ortiz LA, Gambelli F, McBride C, et al. Mesenchymal stem cell engraftment in lung is enhanced in response to bleomycin exposure and ameliorates its fibrotic effects. Proc Natl Acad Sci USA 2003; 100: $8407-11$.

[10] Rojas $\mathrm{M}, \mathrm{Xu} \mathrm{J}$, Woods CR, et al. Bone marrow-derived mesenchymal stem cells in repair of the injured lung. Am J Respir Cell Mol Biol 2005; 33: 145-52.

[11] Gupta N, Su X, Popov B, Lee JW, Serikov V, Matthay MA. Intrapulmonary delivery of bone marrow-derived mesenchymal stem cells improves survival and attenuates endotoxin-induced acute lung injury in mice. J Immunol 2007; 179: 1855-63.

[12] van Haaften T, Byrne R, Bonnet S, et al. Airway delivery of mesenchymal stem cells prevents arrested alveolar growth in neonatal lung injury in rats. Am J Respir Crit Care Med 2009; 180: $1131-42$.

[13] Aslam M, Baveja R, Liang OD, et al. Bone marrow stromal cells attenuate lung injury in a murine model of neonatal chronic lung disease. Am J Respir Crit Care Med 2009; 180: 1122-30.

[14] Kotton DN, Ma BY, Cardoso WV, et al. Bone marrow-derived cells as progenitors of lung alveolar epithelium. Development 2001; 128: 5181-8.

[15] Harris RG, Herzog EL, Bruscia EM, Grove JE, Van Arnam JS, Krause DS. Lack of a fusion requirement for development of bone marrow-derived epithelia. Science 2004; 305: 90-3.

[16] Krause DS, Theise ND, Collector MI, et al. Multi-organ, multilineage engraftment by a single bone marrow-derived stem cell. Cell 2001; 105: 369-77.

[17] Theise ND, Henegariu O, Grove J, et al. Radiation pneumonitis in mice: a severe injury model for pneumocyte engraftment from bone marrow. Exp Hematol 2002; 30: 1333-8.

[18] Herzog EL, Krause DS. Engraftment of marrow-derived epithelial cells: the role of fusion. Proc Am Thorac Soc 2006; 3: 691-5.

[19] Terada N, Hamazaki T, Oka M, et al. Bone marrow cells adopt the phenotype of other cells by spontaneous cell fusion. Nature 2002; 416: 542-5.

[20] Kotton DN, Fabian AJ, Mulligan RC. Failure of bone marrow to reconstitute lung epithelium. Am J Respir Cell Mol Biol 2005; 33: 328-34.

[21] Chang JC, Summer R, Sun X, Fitzsimmons K, Fine A. Evidence that bone marrow cells do not contribute to the alveolar epithelium. Am J Respir Cell Mol Biol 2005; 33: 335-42.

[22] Dammann CE, Nielsen HC. Regulation of the epidermal growth factor receptor in fetal rat lung fibroblasts during late gestation. Endocrinology 1998; 139: 1671-7.

[23] Dammann CE, Nielsen HC, Carraway KL. Role of neuregulin-1 beta in the developing lung. Am J Respir Crit Care Med 2003; 167 : 1711-6.

[24] Zscheppang K, Dork T, Schmiedl A, Jones FE, Dammann CE. Neuregulin receptor ErbB4 functions as a transcriptional cofactor for sftpb expression the fetal lung. Am J Respir Cell Mol Biol 2011; 45: 761-7.

[25] Livak KJ, Schmittgen TD. Analysis of relative gene expression data using real-time quantitative PCR and the 2(-Delta Delta C(T)) Method. Methods 2001; 25: 402-8.
[26] Post M, Smith BT. Histochemical and immunocytochemical identification of alveolar type II epithelial cells isolated from fetal rat lung. Am Rev Respir Dis 1988; 137: 525-30.

[27] Rosenblum DA, Volpe MV, Dammann CE, Lo YS, Thompson JF, Nielsen HC. Expression and activity of epidermal growth factor receptor in late fetal rat lung is cell- and sex-specific. Exp Cell Res 1998; 239: 69-81.

[28] Zscheppang K, Konrad M, Zischka M, Huhn V, Dammann CE. Estrogen-induced upregulation of $\mathrm{Sftpb}$ requires transcriptional control of neuregulin receptor ErbB4 in mouse lung type II epithelial cells. Biochim Biophys Acta 2011; 1813: 1717-27.

[29] Hoeing K, Zscheppang K, Mujahid S, et al. Presenilin-1 processing of ErbB4 in fetal type II cells is necessary for control of fetal lung maturation. Biochim Biophys Acta 2011; 1813: 480-91.

[30] Dominici M, Le Blanc K, Mueller I, et al. Minimal criteria for defining multipotent mesenchymal stromal cells. The International Society for Cellular Therapy position statement. Cytotherapy 2006; 8: 315-7.

[31] Phinney DG, Kopen G, Isaacson RL, Prockop DJ. Plastic adherent stromal cells from the bone marrow of commonly used strains of inbred mice: variations in yield, growth, and differentiation. J Cell Biochem 1999; 72: 570-85.

[32] Dennis JE, Merriam A, Awadallah A, Yoo JU, Johnstone B, Caplan AI. A quadripotential mesenchymal progenitor cell isolated from the marrow of an adult mouse. J Bone Miner Res 1999; 14: 700-9.

[33] Chen X, Katakowski M, Li Y, et al. Human bone marrow stromal cell cultures conditioned by traumatic brain tissue extracts: growth factor production. J Neurosci Res 2002; 69: 687-91.

[34] Nakano N, Nakai Y, Seo TB, et al. Characterization of conditioned medium of cultured bone marrow stromal cells. Neurosci Lett 2010; 483: 57-61.

[35] Wu S, Suzuki Y, Ejiri Y, et al. Bone marrow stromal cells enhance differentiation of cocultured neurosphere cells and promote regeneration of injured spinal cord. J Neurosci Res 2003; 72: 34351.

[36] Smith BT. Lung maturation in the fetal rat: acceleration by injection of fibroblast-pneumonocyte factor. Science 1979; 204: 1094-5.

[37] Nielsen HC. Epidermal growth factor influences the developmental clock regulating maturation of the fetal lung fibroblast. Biochim Biophys Acta 1989; 1012: 201-6.

[38] Torday JS, Sun H, Wang L, Torres E, Sunday ME, Rubin LP. Leptin mediates the parathyroid hormone-related protein paracrine stimulation of fetal lung maturation. Am J Physiol Lung Cell Mol Physiol 2002; 282: L405-10.

[39] Shannon JM, Pan T, Nielsen LD, Edeen KE, Mason RJ. Lung fibroblasts improve differentiation of rat type II cells in primary culture. Am J Respir Cell Mol Biol 2001; 24: 235-44.

[40] Merrill JD, Ballard RA, Cnaan A, et al. Dysfunction of pulmonary surfactant in chronically ventilated premature infants. Pediatr Res 2004; 56: 918-26.

[41] Wang J, Ding F, Gu Y, Liu J, Gu X. Bone marrow mesenchymal stem cells promote cell proliferation and neurotrophic function of Schwann cells in vitro and in vivo. Brain Res 2009; 1262: 7-15.

[42] Salazar KD, Lankford SM, Brody AR. Mesenchymal stem cells produce Wnt isoforms and TGF-betal that mediate proliferation and procollagen expression by lung fibroblasts. Am J Physiol Lung Cell Mol Physiol 2009; 297: L1002-11.

[43] Torday JS, Zinman HM, Nielsen HC. Glucocorticoid regulation of DNA, protein and surfactant phospholipid in developing lung: temporal relationship between growth and differentiation. Dev Pharmacol Ther 1986; 9: 125-31.

[44] Nielsen HC, Kirk WO, Sweezey N, Torday JS. Coordination of growth and differentiation in the fetal lung. Exp Cell Res 1990; 188: 89-96.

[45] Ortiz LA, Dutreil M, Fattman C, et al. Interleukin 1 receptor antagonist mediates the antiinflammatory and antifibrotic effect of mesenchymal stem cells during lung injury. Proc Natl Acad Sci USA 2007 ; 104: 11002-7.

[46] Lindsay L, Oliver SJ, Freeman SL, Josien R, Krauss A, Kaplan G. Modulation of hyperoxia-induced TNF-alpha expression in the newborn rat lung by thalidomide and dexamethasone. Inflammation 2000; $24: 347-56$.

[47] Murch SH, MacDonald TT, Wood CB, Costeloe KL. Tumour necrosis factor in the bronchoalveolar secretions of infants with the 
respiratory distress syndrome and the effect of dexamethasone treatment. Thorax 1992; 47: 44-7.

[48] Gross I. Regulation of fetal lung maturation. Am J Physiol 1990; 259: L337-44.

[49] Cogo PE, Simonato M, Mariatoffolo G, et al. Dexamethasone therapy in preterm infants developing bronchopulmonary dysplasia: effect on pulmonary surfactant disaturated-phosphatidylcholine kinetics. Pediatr Res 2008; 63: 433-7.

[50] Oshika E, Liu S, Ung LP, et al. Glucocorticoid-induced effects on pattern formation and epithelial cell differentiation in early embryonic rat lungs. Pediatr Res 1998; 43: 305-14

[51] Chelly N, Mouhieddine-Gueddiche OB, Barlier-Mur AM, Chailley-Heu B, Bourbon JR. Keratinocyte growth factor enhances maturation of fetal rat lung type II cells. Am J Respir Cell Mol Biol 1999; 20: 423-32.

[52] Chelly N, Henrion A, Pinteur C, Chailley-Heu B, Bourbon JR. Role of keratinocyte growth factor in the control of surfactant synthesis by fetal lung mesenchyme. Endocrinology 2001; 142: 1814-9.

[53] Barazzone C, Donati YR, Rochat AF, et al. Keratinocyte growth factor protects alveolar epithelium and endothelium from oxygeninduced injury in mice. Am J Pathol 1999; 154: 1479-87.
[54] Panos RJ, Bak PM, Simonet WS, Rubin JS, Smith LJ. Intratracheal instillation of keratinocyte growth factor decreases hyperoxiainduced mortality in rats. J Clin Invest 1995; 96: 2026-33.

[55] Chen L, Tredget EE, Wu PY, Wu Y. Paracrine factors of mesenchymal stem cells recruit macrophages and endothelial lineage cells and enhance wound healing. PLoS One 2008; 3: e1886.

[56] Liu W, Purevdorj E, Zscheppang K, et al. ErbB4 regulates the timely progression of late fetal lung development. Biochim Biophys Acta 2010; 1803: 832-9.

[57] Purevdorj E, Zscheppang K, Hoymann HG, et al. ErbB4 deletion leads to changes in lung function and structure similar to bronchopulmonary dysplasia. Am J Physiol Lung Cell Mol Physiol 2008; 294: L516-22.

[58] Dammann O, Bueter W, Leviton A, Gressens P, Dammann CE. Neuregulin-1: a potential endogenous protector in perinatal brain white matter damage. Neonatology 2008; 93: 182-7.

[59] Zacharek A, Shehadah A, Chen J, et al. Comparison of bone marrow stromal cells derived from stroke and normal rats for stroke treatment. Stroke 2010; 41: 524-30.

(C) Knoll et al.; Licensee Bentham Open.

This is an open access article licensed under the terms of the Creative Commons Attribution Non-Commercial License (http://creativecommons.org/licenses/by-nc/3.0/) which permits unrestricted, non-commercial use, distribution and reproduction in any medium, provided the work is properly cited. 